Otterbein University

Digital Commons @ Otterbein

Mathematics Faculty Scholarship

Mathematical Sciences

2000

\title{
A Primer for Applying Service Learning to Computer Science
}

Pete Sanderson

Otterbein University, PSanderson@otterbein.edu

Kenneth Vollmar

Missouri State University, kenvollmar@missouristate.edu

Follow this and additional works at: https://digitalcommons.otterbein.edu/math_fac

Part of the Computer Sciences Commons, and the Mathematics Commons

\section{Repository Citation}

Sanderson, Pete and Vollmar, Kenneth, "A Primer for Applying Service Learning to Computer Science" (2000). Mathematics Faculty Scholarship. 7.

https://digitalcommons.otterbein.edu/math_fac/7

This Conference Proceeding is brought to you for free and open access by the Mathematical Sciences at Digital Commons @ Otterbein. It has been accepted for inclusion in Mathematics Faculty Scholarship by an authorized administrator of Digital Commons @ Otterbein. For more information, please contact

digitalcommons07@otterbein.edu. 


\title{
A Primer for Applying Service Learning to Computer Science
}

\author{
Pete Sanderson and Ken Vollmar \\ Computer Science Department \\ Southwest Missouri State University \\ Springfield, MO 65804 \\ \{PeteSanderson, KenVollmar\}@mail.smsu.edu
}

\begin{abstract}
Service learning is an educational philosophy that promotes active learning through community service. We have recently applied this approach in our computer science curriculum, specifically to our software engineering course. In order that other computer science departments can benefit from our experience, we have developed a primer one can follow to establish a program for service learning in the computer sciences. We also describe and assess our experience after one year of applying service learning to software engineering.
\end{abstract}

\section{What is Service Learning?}

Service learning is an educational philosophy based on the integration of classroom concepts and related community service experience. One key is reflection; Hatcher and Bringle [2] emphasize that students should "reflect on their (community) involvement in such a way as to gain further understanding of course content and of the discipline and its relationship to social needs and an enhanced sense of civic responsibility." These relationships are embodied in the Kolb Learning Cycle, a conceptual framework for experiential learning [3]. Each phase of the cycle represents learning activities: concrete experience $\rightarrow$ reflective observation $\rightarrow$ abstract conceptualization $\rightarrow$ active experimentation. Learning can begin at any phase but the entry point varies from individual to individual depending on learning styles and prior knowledge.

The most critical transition for long-term learning is from concrete experience to abstract conceptualization. Kolb relates them through reflective observation, defined as "the intentional consideration of an experience in light of particular learning objectives [2]." Students should have not only the opportunity to reflect on their experiences, but a framework to guide their reflection.

Service learning is related to active/passive learning theory. The amount you remember is directly proportional to your level of involvement in the learning process. This is often illustrated with the Cone of Learning [1]. Passive learning practices, such as reading or looking at pictures, result in retention rates of $10-30 \%$. Active learning practices, such as giving a talk or doing an activity, increase retention to $70-90 \%$. Service learning relates to a number of active learning strategies, especially collaborative learning and problem-based learning.

The above definition of service learning includes the phrase "related community service." Service learning is not simply academic credit for volunteer work and community service. Successful service learning also requires that the service experience be related to classroom concepts. The emphasis must on learning, not service[8]. Consider this a principle of service learning; it is your responsibility as instructor and discipline expert to assure that all persons involved understand it. Institutional support for service learning must come from the academic area (provosts, deans), rather than units such as student affairs or campus ministries [6].

\section{Benefits of Service Learning}

Service learning experiences benefit students in many ways besides the experiential learning benefits described above. The experiences are great resume builders, having many of the benefits of internships with smaller time commitments. Successful service learning experiences build selfconfidence and allow students to "test drive" their career choices before graduation. They also provide valuable training in citizenship, by exposing students to larger societal issues they may have previously avoided or seen only as abstractions. Finally, they connect students to the community outside the university in a way that benefits all. 
There are benefits to faculty as well. Students enrolled in service learning contribute to more interesting and interactive discussions in the companion course. It is also gratifying when such students share their epiphany, the moment when they make the connection from the concrete to the abstract. Other benefits are more direct, such as the opportunity to apply research theories through carefully designed service learning projects or to make contacts for future consulting.

Tangible benefits to the department and institution include increased visibility through publicity of novel or successful service learning projects in professional publications and conferences as well as community media. Visibility and positive publicity lead to increased numbers of majors and enhanced funding opportunities.

\section{Institutional Support for Service Learning}

Southwest Missouri State University has formalized service learning through the office of Citizenship and Service Learning (URL in Table 1), or CASL. The CASL director reports directly to the Vice-President of Academic Affairs. The office was established in 1996, based on the Rutgers University model (URL in Table 1). Service learning courses were first offered in the Fall 1997 semester, and by Spring 1999 the number of courses offered had nearly quadrupled and the number of enrolled students increased five-fold. The office currently serves 131 community partners (agencies) locally.

Service learning courses at SMSU are one-hour courses offered in conjunction with regular discipline-based courses. This separation allows departments to implement service learning with minimal impact to their curriculum. Select an existing course, develop an additional one hour component directed toward service learning, and offer both. In our case, the companion software engineering course is required but the service learning course is elective. About $20 \%$ of our software engineering students take it.

Our CASL office has developed requirements that both the service learning course and its companion course must follow. The service learning course is a one-hour, separately graded course that requires at least 40 hours of unpaid community service. Instructors are encouraged to include reflection exercises such as essays or diaries. Both it and its companion course must be upper-division or graduate level. The companion course cannot require concurrent enrollment in the service learning course.

CASL promotes and supports service learning through a number of services. One example is community outreach to identify community partners and match them with interested faculty and students. Another is assistance in course administration, such as responsibility for student timesheets and community partner evaluations of students. They also provide faculty development opportunities.

These services are much appreciated by faculty, since service learning is taught on an overload basis (no teaching load credit, release time, or stipend) at our institution. For further information, contact the authors or visit the CASL web page listed in Table 1.

\section{Department Support for Service Learning}

When all is said and done, responsibility for service learning delivery lies in the departments. The department should above all support the service learning philosophy and pedagogy. This has not been a problem at our institution, given the wonderful CASL support mechanism. Once this is established, departmental steps toward realizing the benefits of service learning are:

1) Propose the service learning course and see it through the approval process

2) Carefully and selectively designate companion courses that fit the CASL guidelines. This should be initiated by individual faculty members rather than by the department chair or a committee.

3) Encourage enrollment not by requiring it but by convincing students of the benefits. The department can also utilize more explicit methods such as scholarships to cover service learning course tuition.

4) Support service learning faculty in any way possible.

The faculty member planning to offer a service learning component should:

1) Build relationships with the CASL office, if it exists. Take advantage of available faculty development opportunities.

2) Survey the service learning literature. See the Reference list for select readings, especially Miller's work relating science to society [5]. In addition, Table 1 lists a number of URLs relevant to service learning and computer science.

3) Initiate or participate in the course and companion approval process.

4) Determine which community partners provide appropriate experiences, and communicate with them.

5) Develop service learning course syllabi, including learning objectives and reflection assignments.

We in Computer Science followed all these steps starting late in 1997 and offered our first Service Learning in Computer Science course in Fall 1998. We considered three candidates for companion courses: networks, databases, and software engineering. We selected Introduction to Software Engineering, and are currently offering it with service learning for the third time. 


\section{Experience with Software Engineering}

Software Engineering, our companion course, has an advanced data structures (e.g. CS 7) prerequisite and is normally taken late in the junior or early in the senior year. It overviews software lifecycle models and activities at all phases of development and maintenance. About one half of the course grade is based on a semester-long team project in software development. Teams of 3-4 students are assigned a project and expected to conduct requirements analysis and specification, prototype development, design development, code implementation and testing, and to produce associated documentation.

Software engineering was selected as our first companion course because the team project naturally fits the service learning philosophy. Students who enroll in Service Learning form a team and develop a customized application for the community partner as their software engineering project. By organizing the service learning experience in this way, not only is its relationship to the companion course explicit, but the community partner also gets a higher quality product than would be expected from an equivalent one credit hour effort (such as an independent study). To date, three students have enrolled each semester (about $20 \%$ of all software engineering students).

\subsection{Service Learning Course}

Our service learning course is Service Learning in Computer Science. It is a one-hour upper division course that counts toward a computer science major's nine hours of computer science electives. The service learning component is graded separately from the software engineering course. It is desirable but not required that the same instructor teach the service learning component and companion course.

A student's grade in our Service Learning course is based on several components:

1) Each student must log at least 40 hours of service work. CASL policy dictates a failing grade if this requirement is not met. The student, the community partner, and a CASL administrator sign log sheets. These hours are to be in addition to those required for the companion course.

2) Each student is required to meet with a CASL administrator at the community partner site for a performance evaluation. This occurs about midsemester.

3) The community partner is required to submit a student evaluation form provided by CASL.

4) Each student is required to submit a series of essays describing specific aspects of the project and the service learning experience.

5) The team is required to give at least one oral presentation about the project and service learning.
This requirement has been met in the past by addressing a student ACM meeting.

\subsection{Project Selection and Preparation}

Because the project involves development of software applications for external clients, a number of issues should be resolved before project development begins. Many require the instructor's experience and should not be the students' responsibility. The issues addressed here apply to any project developed for an external client, but are particularly important for a service learning project. Community partners frequently are social service agencies that rely on scarce government funding and volunteer labor, and are unlikely to have computer science or data processing professionals on staff to provide support and assistance.

1) Select or at least approve the project. Communicate with the community partner to assure that the project:

a) Meets the main service learning goal of applying concepts taught in the course.

b) Is of appropriate scale for the course project.

c) Is of appropriate level of difficulty for the course and students involved.

2) Make sure that the community partner is prepared to devote resources. You need answers to these questions.

a) What computer equipment and development software do they have or plan to acquire?

b) What limitations are there on student access to their computer facilities?

c) Who will be their project liaison, so students can have a single point of contact for decisions?

d) Make sure they understand the liaison will have to devote time to the students and the project, especially during requirements analysis, specification and prototyping.

3) Make sure the community partner understands the limitations of a one-semester project. Negotiate the answers to these questions.

a) How much maintenance (if any) will be provided? If corrective or perfective maintenance is desired, the students may have graduated and moved away.

b) How much training will be provided?

c) What documentation will be included?

d) What if the project fails to be completed, or does not meet the requirements?

4) Write a license agreement for the community partner to sign. A sample agreement is available at http://www.cs.smsu.edu/ pete/csc300. It should cover the issues from the previous list, plus liability and other disclaimers. Privacy protection is especially important for social service agencies whose client databases contain sensitive and private individual 
information. You may wish to consult your institution's attorney.

5) Communicate both with the students and the community partner as the project progresses and intervene if necessary to adjust the scope or details of the project.

\subsection{Projects Completed}

We are currently offering the Service Learning course for the third semester. From the beginning, we intended to limit our participation to one student team per semester, and by coincidence the number of students enrolled in the service learning component has been three per semester. The IEEE and others recommend five as the optimal size for software engineering project teams. We have publicized the service learning component through promotional flyers, visits during the previous semester to meetings of the prerequisite course, and presentations during the first week of class in the software engineering course.

The three projects have been for three different community partners but are quite similar in nature. All have been database management applications. The Fall 1998 team developed a PC-based database management application for the Family Violence Center, an agency for abused women and their children. The software maintains records of clients participating in a federally funded job training program. This program has stringent record-keeping and reporting requirements that must be met for annual grant renewal. The record keeping and reporting had previously been done manually, and the database system was greatly appreciated.

The Spring 1999 team developed a comprehensive database application to support The Kitchen, an agency that provides a variety of services for those in need, including food, housing, clothing, day care, jobs and job training. The emphasis for this project was to consolidate and provide a consistent user interface to a number of separate client databases.

The greatest challenge to both teams proved to be logistical rather than technical. Client interactions were sometimes frustrating. Meeting times were difficult to set due to the off-campus setting and conflicts between student and client schedules. The client administrators were in some cases volunteers and missed project meetings. The liaison from one community partner became seriously ill partway through the semester and his replacement was not familiar with the project. All are character-building challenges that the service learning experience can provide.

The Fall 1999 team is also developing a consolidated database application. Their client is The Discovery Center, a hands-on children's science museum.

\section{ASSESSMENT}

Assessment is crucial to the academic integrity of service learning. We include two kinds of assessment from the perspectives of all involved. One is assessment of student performance for grading purposes and the other is assessment of service learning as we have applied it to software engineering for two semesters.

\subsection{Student Assessment}

Software engineering students in the Fall 1998 and Spring 1999 classes were given a project questionnaire along with their regular student evaluation form near the end of the semester. It included sixteen multiple-choice questions and three essays. Twelve of the multiple-choice questions are of interest for this assessment. Students were not individually identified, but one of the questions asked them to identify their project. From this, we grouped the responses according to Service Learning enrollment and client type. A total of 23 students were surveyed and we partitioned them into three groups: the 6 students doing Service Learning projects (external clients), the 6 students doing other projects with external clients, and the 11 students doing projects with the instructor as client. Table 2 compares the percentages of students in each group who gave the strongest positive response to the twelve selected questions.

Due to the limited sample size and some seemingly contradictory values, we have not performed statistical tests of significance. For instance, the data show that Service Learning students are much less satisfied with their choice of projects than the other groups yet much more likely to recommend their project to future students!

\subsection{Community Partner Assessment}

Community partners evaluate each student near the end of the semester using a form provided by the CASL office. A copy of the evaluation is provided to the instructor in time for grade determination. The evaluation form currently in use asks the community partner to evaluate the strengths and weaknesses of the student, and to describe the student's accomplishments.

In general, the community partners are very grateful to receive the services of our talented computer science students. We faculty try to assure that the project scope is such that the student team is able to carefully design, implement, test and document the software and train the client, all in one semester.

\subsection{CASL Assessment}

The CASL office evaluates each student during an onclient-site visit about halfway through the semester. A copy of their report is given to the faculty for possible use in grade determination. The evaluation form currently in 
use has a list of questions for the student to answer concerning their experience so far, a list of questions for the agency to rate the student, and a comments section.

The CASL office has been quite pleased with the computer science students and projects. Both teams have been featured in the CASL newsletter and in the summer 1999 edition of the faculty/staff/alumni newsletter. We have also generated some publicity through a previous conference publication [7].

\subsection{Faculty Assessment}

Students completing the service learning component are assigned a letter grade based on the criteria outlined in Section 5.1. The CASL requirement of 40 hours of on-site service is difficult to meet since it is in addition to any requirements of the companion course. Students are able to meet this requirement through a number of activities: discussing requirements, iterating through several prototypes, installing software, training agency personnel and diligently documenting the system.

From our experience so far, it is obvious that service learning can be applied to other courses in our curriculum. Our new database course would be suitable of course, as would our networking course. The CASL upper-division requirement prevents us from emulating other efforts such as designing WWW pages for the community as a CS2 project [4]. We and our colleagues will explore other possibilities in the years ahead.

\section{References}

[1] Dale, E. Audio-visual Methods in Teaching, Holt, Rinehart and Winston

[2] Hatcher, J. and Bringle, R. Reflection: Bridging the gap between service and learning. College Teaching 45:4 (1997).

[3] Kolb, D. Experiential Learning: Experience as the source of learning and development, PrenticeHall, 1984.

[4] LeBlanc, M. Service learning in computing. The Journal of Computing in Small Colleges 14:4 (1999), 173-181.

[5] Miller, S. Science and Society: Redefining the Relationship, published by Campus Compact (available from Campus Compact, Box 1975, Brown University, Providence, RI 02912), 1996.

[6] Morton, K. Issues related to integrating servicelearning into the curriculum," in Service-Learning in Higher Education, Barbara Jacoby and Associates (Editors), Jossey-Bass Publishers, San Francisco, 1996.

[7] Sanderson, P. Service learning in computer science, The Journal of Computing in Small Colleges 12:4 (1999), 341-344.

Zlotkowski, E. Linking service-learning and the academy. Change, January/February 1996.

\begin{tabular}{|l|}
\hline $\begin{array}{l}\text { Big Dummy's Guide to Service Learning } \\
\text { www.fiu.edu/ time4chg/Library/bigdummy.html }\end{array}$ \\
\hline Campus Compact \\
www.compact.org \\
\hline $\begin{array}{l}\text { Eastern Michigan University } \\
\text { www.emich.edu/public/office asl/home.html }\end{array}$ \\
\hline $\begin{array}{l}\text { Indiana University/Purdue University, Indianapolis } \\
\text { www.psyunix.iupui.edu/service.htm }\end{array}$ \\
\hline $\begin{array}{l}\text { National Service-Learning Clearinghouse } \\
\text { www.nicsl.coled.umn.edu }\end{array}$ \\
\hline $\begin{array}{l}\text { Rutgers University } \\
\text { www.scils.rutgers.edu/case/case.html }\end{array}$ \\
\hline $\begin{array}{l}\text { Science, Engineering, Architecture, Math, CS (SEAMS) } \\
\text { www.compact.org/awards/seams.html }\end{array}$ \\
\hline $\begin{array}{l}\text { Southwest Missouri State University CASL } \\
\text { www.smsu.edu/casl }\end{array}$ \\
\hline $\begin{array}{l}\text { Stanford University } \\
\text { haas.stanford.edu }\end{array}$ \\
\hline $\begin{array}{l}\text { University of California - Berkeley } \\
\text { www-gse.berkeley.edu/research/slc/ServiceLearning.html }\end{array}$ \\
\hline
\end{tabular}

Table 1. Selected Service Learning WWW Resources. List current as of December $1999 . \quad$ Check www.cs.smsu.edu/ pete/csc300 for updates.

\begin{tabular}{|l|c|c|c|}
\hline Question & $S L$ & EXT & INST \\
\hline Requirements analysis crucial & 50 & 40 & 27 \\
\hline Prototyping crucial & 33 & 67 & 18 \\
\hline Much more time on requirements vs. coding & 67 & 17 & 73 \\
\hline Definitely satisfied with project choice & 17 & 100 & 45 \\
\hline Definitely satisfied with project results & 17 & 80 & 45 \\
\hline Definitely helped learn course material better & 83 & 67 & 55 \\
\hline Frequently share experiences outside of class & 67 & 20 & 55 \\
\hline Frequently share experiences in class & 33 & 20 & 27 \\
\hline Definitely helped you participate in class & 17 & 33 & 9 \\
\hline Definitely relevant to course material & 50 & 17 & 36 \\
\hline Definitely resembles real-world experience & 50 & 50 & 10 \\
\hline Definitely recommend to future students & 83 & 33 & 9 \\
\hline
\end{tabular}

Table 2. Percentage of students giving the most positive response to questions concerning the Software Engineering project. Groups are: Service Learning Students (SL), other students with external project clients (EXT), students with instructor as client (INST). 